\title{
Comparison of Three Macroinvertebrate Sampling Methods for Use in Assessment of Water Quality Changes in Flashy Urban Streams
}

\author{
Roger Yeardley Jr. ${ }^{1}$, Scott Jacobs ${ }^{1}$, Ken Fritz ${ }^{1}$, William Thoeny $^{2}$ \\ ${ }^{1}$ Office of Research and Development, U.S. Environmental Protection Agency, Cincinnati, USA \\ ${ }^{2}$ Pegasus Technical Services, c/o U.S. Environmental Protection Agency, Cincinnati, USA \\ Email: yeardley.roger@epa.gov
}

How to cite this paper: Yeardley Jr., R. Jacobs, S., Fritz, K. and Thoeny, W. (2020) Comparison of Three Macroinvertebrate Sampling Methods for Use in Assessment of Water Quality Changes in Flashy Urban Streams. Journal of Environmental Protection, 11, 585-609.

https://doi.org/10.4236/jep.2020.118035

Received: June 2, 2020

Accepted: August 2, 2020

Published: August 5, 2020

Copyright ( 2020 by author(s) and Scientific Research Publishing Inc. This work is licensed under the Creative Commons Attribution International License (CC BY 4.0).

http://creativecommons.org/licenses/by/4.0/

\section{(c) (i) Open Access}

\begin{abstract}
The unique challenges associated with sampling of macroinvertebrates in flashy urban streams create a methods gap. These streams form isolated pools for much of the year, interspersed with spates that scour and deposit excessive amounts of sediment. Commonly used stream grab sampling methods, such as nets and Hess and Surber fixed-area samplers, work well in wadable streams with perennial flow. Deployed samplers (Hester-Dendy, gravel tray) can be used in waters with or without flow. We evaluated three methods which don't require stream flow: modified Hester-Dendy (MHD), gravel tray, and bucket (a type of cylinder grab sample method), for their potential use in bioassessment of a project involving daylighting of a 180-m culvert on Congress Run, a flashy urban tributary to Mill Creek in Cincinnati, Ohio. Method efficacy was measured using three criteria: usability (level of effort and recoverability of samplers), variability, and community retrieval completeness. The bucket method required the lowest level of effort and had the highest sample recovery. The bucket sampler had the lowest variability for most metrics, including the critical metric of taxa richness, with a coefficient of variation (CV) of $20.9 \%$. The MHD and tray samplers had taxa richness CVs of $42.9 \%$ and 53.9\%, respectively. The bucket sampler also had the lowest CV (27.4\%) for a multi-metric index. The bucket sampler performed best with respect to community retrieval completeness, with higher pooled and average taxa richness. The total number of taxa collected from all the replicate bucket grab samples (42) was greater than that collected by the HD and tray samplers combined (27). Multivariate analyses showed significant grouping with respect to methods and location. This study supports the bucket grab sampler method as a candidate for sampling of flashy urban streams.
\end{abstract}




\section{Keywords}

Macroinvertebrate, Methods, Stream, Urban, Sampling, Flow, Hydrology

\section{Introduction}

Bioassessment through sampling of macroinvertebrate communities is a well-established means of measuring the effects of multiple stressors on stream water quality. Changes in macroinvertebrate communities can be used to assess the success of stream restoration and Green Infrastructure (GI) projects. For the widely used means of sampling macroinvertebrates in streams, flow is either required or highly recommended. The flow regime of flashy urban streams results in a series of interspersed and poorly connected pools at baseflow alternating with brief but destructive flooding events. These physical/hydrological conditions pose challenges to common sampling methods. Therefore, none of the popular sampling methods are ideal for bioassessment of flashy streams.

There are a significant number of streams suffering from the effects of urbanization, including flashy flow from high percentages of impervious surfaces. In 2000, the U.S. EPA [1] estimated that over $130,000 \mathrm{~km}$ of streams in the U.S. were impaired by urbanization. This number has likely increased significantly in the two decades since that report. Many of these urban streams would be expected to be intermittent or ephemeral and consist of a series of pools for much of the year, and to not have the requisite flow to effectively use these popular methods. This indicates a significant methods gap regarding an effective macroinvertebrate sampling method for sampling flashy urban streams.

Stressors in urban streams include contaminant input, which can come from sources such as sanitary sewer overflows (SSOs), combined sewer overflows (CSOs), industrial discharges, septic systems, wastewater treatment plant effluents, irrigation, and roadway runoff. However, there is evidence that the biotic integrity of streams, as measured by their macroinvertebrate communities, can be determined as much by alterations in hydrology and stream flow regimes [2] [3] as by contaminant input. For instance, Hawley et al. [4] found that a reference stream went from a biotic integrity index rating of "excellent" to a rating of "poor" (and saw similar decreases in metrics like taxa richness) in a year with an unusually high frequency of critical discharge events, which mobilized the stream bed enough to significantly disturb the benthic macroinvertebrates. Flashy flow regimes, with relatively high peak flows and low base flows [3] [5] [6] are caused or exacerbated by the high percentage of impervious surfaces in urban drainage basins. This flashiness, part of an "urban stream syndrome" [6], can result in streambed scouring and sediment mobilization episodes combined with low to no flow during much of the year.

There are a number of macroinvertebrate sampling methods historically used to sample streams. Nets (e.g., D-frame, kick net) are generally considered a 
qualitative to semi-quantitative method and are the most widely used method by government environmental agencies in the U.S. [7] [8] [9] [10] [11] and around the world [12]. For these methods, macroinvertebrates dislodged from the substrate are carried by flowing stream water into the nets, and thus these methods largely require stream flow. Fixed-area grab samplers (e.g., Surber, Hess, bucket/cylinder) are quantitative methods that are widely used [7] [9] [10] [12] [13] and give a "snapshot" of stream conditions. Ohio EPA [11] uses Surber samplers in their assessment of headwater streams. Surber and Hess fixed-area samplers also take advantage of stream flow to wash invertebrates into nets positioned downstream of the sampling area.

Deployed artificial substrate samplers, which are deployed in a water body at one point in time and retrieved and processed later (usually a period of weeks), can give an integrated picture of water quality. Two of the most common types of deployed artificial substrate samplers are Hester-Dendy (HD) multi-plate samplers and rock baskets or gravel trays [7] [14]. Hester-Dendy multi-plate artificial substrate samplers are used by the U.S. EPA, USGS, and several state environmental agencies [7] [9] including Ohio EPA [15] [16] [17]. The Ohio EPA [15] [16] [17] recommends a flow of $\geq 10 \mathrm{~cm} / \mathrm{sec}$ for use of Hester-Dendys in Ohio streams. The Iowa Department of Natural Resources [18] recommends a flow of approximately $15-50 \mathrm{~cm} / \mathrm{sec}$ for their standard Hester-Dendys. IDNR has a special low-flow modified Hester Dendy, but some flow is recommended for use of this as well. Though some government agencies recommend a certain level of flow for use of HDs and gravel trays in streams and other lentic habitats, these artificial substrates can provide habitat for macroinvertebrates to colonize, regardless of flow presence and thus their use does not require flow. Another method which does not require stream flow, a cylinder fixed-area sampling method using a bucket [13], would also seem to be a candidate for sampling the pools that exist for much of the year in flashy urban streams.

Bioassessment of benthic macroinvertebrate communities was chosen as one element of a research project assessing the effectiveness of a GI project daylighting a culvert on Congress Run stream, in the Congress Run-Mill Creek hydrological unit code (HUC) \#050902030105 (Figure 1) in Cincinnati, Ohio. The Congress Run HUC drains $77.6 \mathrm{~km}^{2}$ and has the significant amount of impervious surfaces that would be expected to accompany 79\% developed land [19] [20]. GI technologies, such as rain gardens, green roofs, permeable pavements, and daylighting, encourage a more natural flow of water. Daylighting projects, like that at Congress Run, involve restoration of stream sections that have been channelized and diverted through pipes. Daylighting and related efforts help to reverse channelization and concentration of flow in streams and rivers caused by culverts, pipes, and concrete lining of streams. Other GI technologies encourage more infiltration of water from precipitation (with more immediate storage and groundwater recharge) through plants and soils, and more evapotranspiration, as opposed to direct runoff from impervious surfaces of roads and urban structures. 


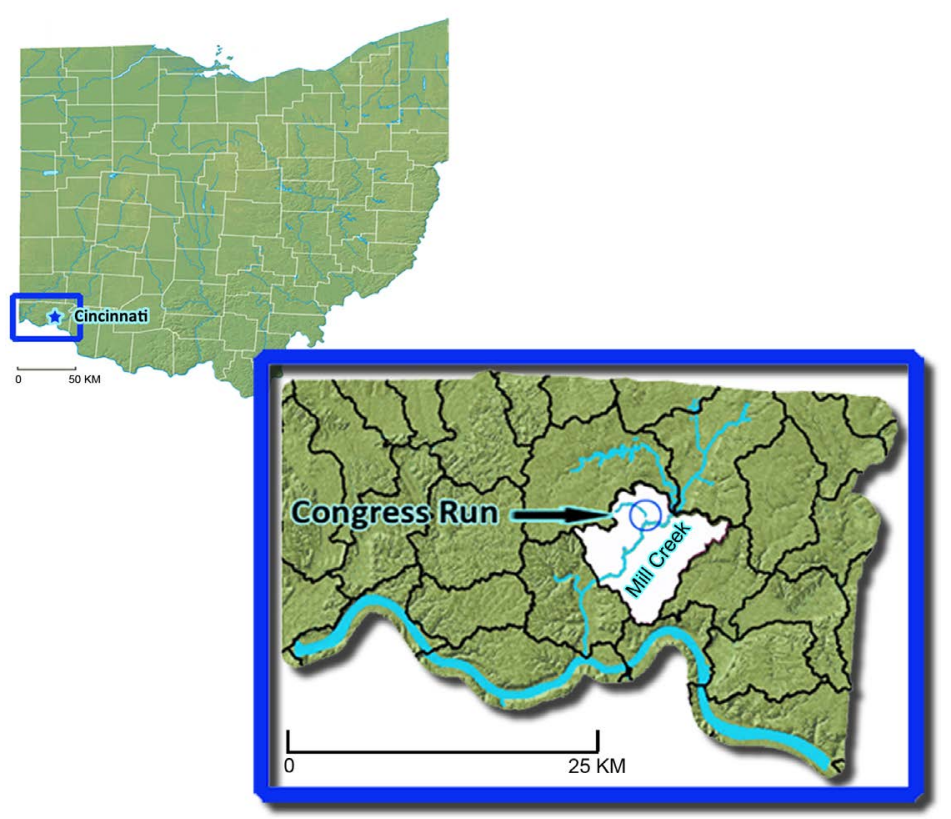

Figure 1. Study area-Congress Run, tributary to the Mill Creek in Cincinnati, Ohio near its confluence with Mill Creek. Hydrologic unit in which Congress is situated (HUC-12 \# 050902030105) highlighted in white. Insert is Hamilton County, in which Cincinnati is located.

To maximize the ability to detect differences in communities before and after remediation or GI projects or in different reaches, a macroinvertebrate sampling method is desired that is usable in a stream with flashy flow patterns, has a relatively low variability, and achieves as complete as possible retrieval of the taxa present in that stream reach. We compared the efficacy in assessing pool habitat in a flashy urban stream of three methods which don't require steam flow: bucket grab sample, gravel tray, and modified Hester-Dendy (MHD), with respect to these criteria. The method that rated the best with respect to these criteria would then be used for continued bioassessment before and after daylighting to help evaluate whether this GI project had resulted in improvement of stream condition.

\section{Materials and Methods}

\subsection{Physical Measurements}

Stream flow was measured (Swoffer Model 3000) in the middle of the water column (3 replicate measurements) near the upstream entrance to each pool where the flow would be expected to be greatest and therefore most detectable in these low flow conditions. Sediment size composition and organic content were characterized to assess whether differences in sediment characteristics among methods affect the macroinvertebrate communities recovered by each method. For the MHD and tray samples, the sediment characterized represented that which was deposited on them during the deployment period. Sediment particle size fractions were analyzed by wet and dry sieving of the sediments collected by 
bucket, tray, and HD samples after the sediment samples were sorted and macroinvertebrates removed. Contents of each jar containing the sorted sample were rinsed onto a $2 \mathrm{~mm}$ sieve stacked on top of a $250 \mu \mathrm{m}$ sieve. Sediment on the $2 \mathrm{~mm}$ sieve was swirled and rinsed until particles $<2 \mathrm{~mm}$ were passed through the sieve and collected on the $250 \mu \mathrm{m}$ sieve. Contents of the sieves were transferred to pre-ashed aluminum pans, air-dried, then oven-dried for 24 hours at $50^{\circ} \mathrm{C}$, followed by ashing in a muffle furnace for 3 hours at $550^{\circ} \mathrm{C}$. Ash-free dry mass (AFDM) procedures based on ASTM methods [21] [22] were used to measure the total dry weight of sediment, the organic and inorganic sediment weights and percentages of two sediment size fractions $-250 \mu \mathrm{m}$ to $2 \mathrm{~mm}$ (fine particulate organic matter (FPOM) for the organic portion), and $>2 \mathrm{~mm}$ (coarse particulate organic matter (CPOM) for the organic portion). As a rough measure of larger sediment particles, medium to coarse gravel and larger [23] [24], the $>2 \mathrm{~mm}$ fraction was dry sieved in a $5.6 \mathrm{~mm}$ sieve and the weight of this larger size fraction also recorded. These analyses do not account for fines and silt as these were lost in the initial sieving of sediments at $250 \mu \mathrm{m}$ to recover macroinvertebrates.

\subsection{Samplers}

\subsubsection{Gravel Trays}

The trays used to hold the gravel were plastic Ziploc ${ }^{\mathrm{TM}}$ Small Square containers (1.5 Pt./709 ml). One-inch holes were drilled in the bottom and sides to allow connectivity with the stream water and sediment; four holes on the bottom and two on each side. Between 1300 and $1400 \mathrm{~g}$ of Vigoro $^{\mathrm{TM}}$ brand natural river rock, ranging in diameter from 1.5 to $5 \mathrm{~cm}$, was loaded into each tray. Depending on the classification scheme, this size range of rocks would be classified as a mix of gravel and pebbles [23] [25] or as gravel [24] [26] [27]. Gravel volume and interstitial space were measured by a liquid displacement method. After weight and volume of gravel were measured, each filled tray was covered with two layers of $1.9 \mathrm{~cm}$ square-opening cotton/nylon mesh/fishing net to prevent stream flow from dislodging gravel during deployment (Figure 2(a) and Figure 2(c)). Mesh was fastened to the trays with zip ties. These samplers had an average of around $200 \mathrm{ml}$ of interstitial space for macroinvertebrates to attach and occupy, and a cross-sectional area/ footprint of $195 \mathrm{~cm}^{2}$.

\subsubsection{Modified Hester-Dendys (MHDs)}

The design of the multi-plate samplers [28] used in this study was a low-profile modification of versions used in previous studies [14] [15] [16] [17]. Each sampler was made up of eight rectangular Masonite/hardboard plates $(3.8 \times 15.2 \mathrm{~cm}$ each) separated by nylon washers ( $3 \mathrm{~mm}$ thick, $8 \mathrm{~mm}$ Hole Size, $8 \mathrm{~mm}$ ID, 22 $\mathrm{mm} \mathrm{OD}$ ) and held together by two eyebolts (Figure 2(b) and Figure 2(c)). There were 2 widths of spaces in each HD, 3 spaces between plates created by single spacers, and 3 spaces created by double spacers. Each of these samplers offers the same area for colonization as an Ohio EPA style HD. Our MHDs offer 


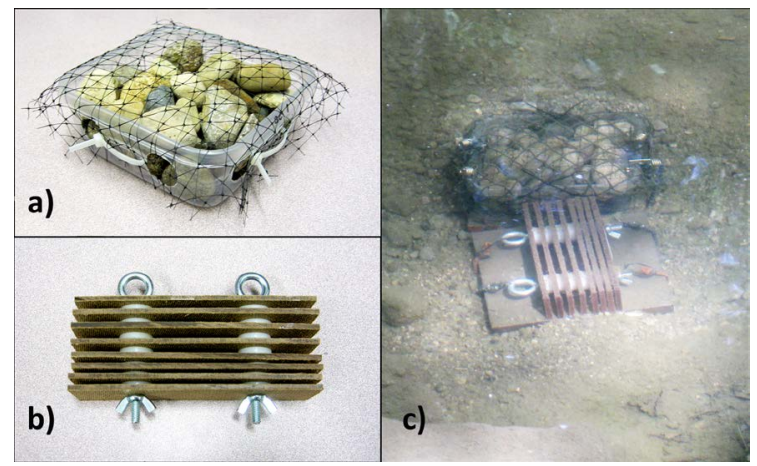

Figure 2. Deployed samplers: tray and low-profile Hester-Dendy. (a) Assembled gravel-filled tray; (b) Assembled modified Hester-Dendy (MHD); (c) Gravel tray and Hester-Dendy deployed in a pool on Congress Run.

the same area per plate $\left(58.1 \mathrm{~cm}^{2}\right)$ as the Ohio EPA's $76.2 \times 76.2 \mathrm{~cm}(3 \times 3$ ") plates, and also have 8 plates per HD. These "low profile" MHDs were designed to stay submerged in pools and riffles of headwater streams, which are often shallow, and to provide less resistance to flow during times of high discharge. Each sampler has $158 \mathrm{ml}$ of interstitial space for macroinvertebrates to attach and occupy, and a cross-sectional area/footprint of $96.8 \mathrm{~cm}^{2}$.

\subsubsection{Bucket Grab Samplers}

The bucket grab sampling method was based on that described by Fritz et al. [13]. The equipment included an 18.9 L (5 gallon) bucket (Figure 3), with the bottom removed and the bottom edge modified to be serrated. This type of sampler works best in areas without concentrations of larger substrate such as cobble and boulders, and with some combination of silt, sand, and fine through medium gravel into which the bucket can be pushed. Other important equipment included a small hand net ( 250- $\mu \mathrm{m}$ mesh), a small plastic tub, $250 \mu \mathrm{m}$ sieve, squeeze bottle(s), and sample containers and ethanol for stream side preservation of the sample. The $25.4 \mathrm{~cm}$ (10 in.) diameter bucket delineates a $506.7 \mathrm{~cm}^{2}$ sampling area.

\subsection{Sampling Process}

Five pairs of MHD and gravel tray samplers were deployed in the deeper parts of pools upstream and downstream from the culvert. The locations of the samplers within these pools are shown in Figure 4. The MHD samplers were situated with the plates perpendicular to stream flow. At the stream site, to better anchor them, MHD and gravel tray samplers were attached to paving stones or steel plates $(15.2 \times 15.2 \times 1.9 \mathrm{~cm}$ ) with elastic cords (Figure $2(\mathrm{c}))$. The samplers were deployed in the stream for 6 weeks. After 6 weeks deployed samplers and grab samples were collected (in a downstream to upstream order) over a five-day period in June 2017. No significant rain events occurred during this five-day period (Figure 6). When the buried trays and MHDs were dug up, the several centimeters of sediment on top was not part of the sample analyzed for macroinvertebrates, only the sediment in the samplers themselves. Bucket grab 


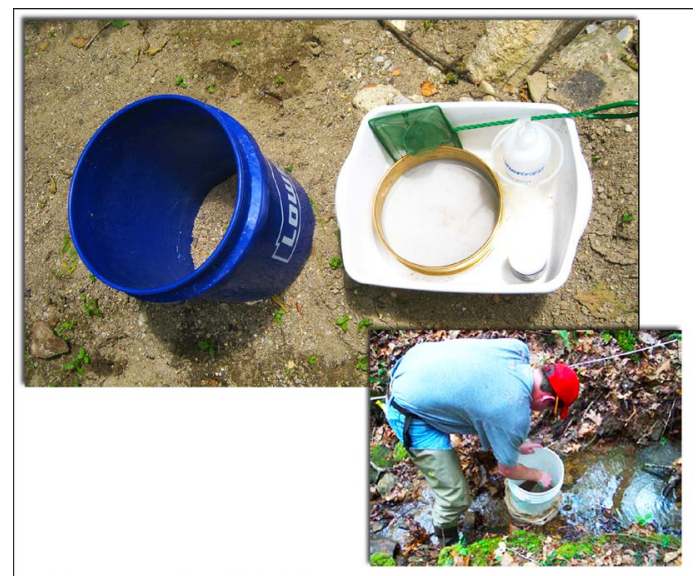

Figure 3. Bucket grab sampling method, showing equipment and sampling being performed.

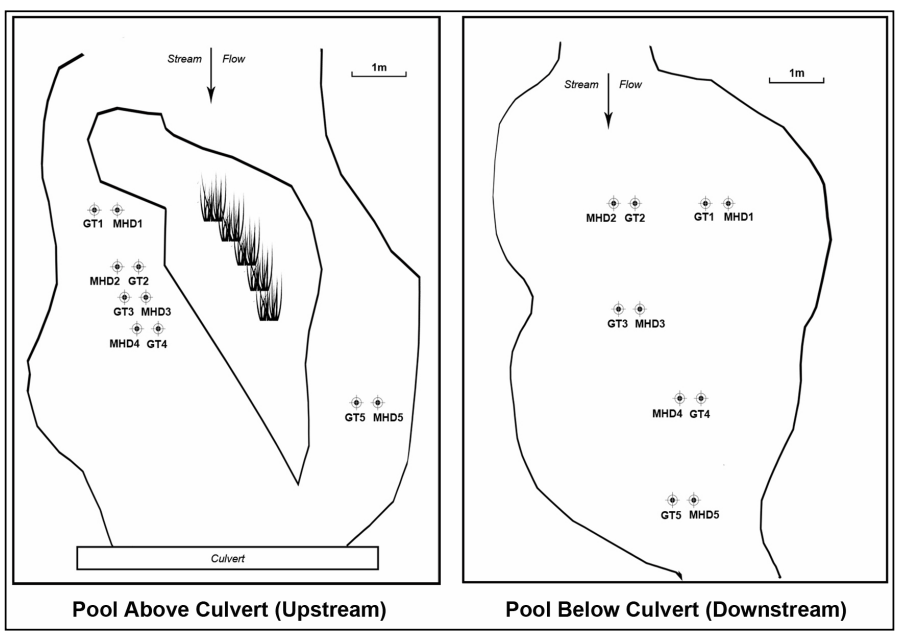

Figure 4. Illustration of the locations of the MHD and tray samplers in the upstream and downstream pools.

samples were collected in the pools near the locations, along the same transects as the MHD and tray samplers on the same day or within one day of retrieval of these deployed samplers. Water depth at each sampler was measured at the start and end of the deployment. MHD and tray samples were put into resealable plastic bags and kept on ice in a cooler until processed at the lab. Sample processing began within 3 hours of retrieval of the first sample. All samples were sieved with USA. Standard No. 60 sieves $(250 \mu \mathrm{m})$ and preserved on the day of collection in $80 \%$ ethanol.

Bucket, or "stovepipe" samplers have been shown useful in shallow aquatic habitats with little or no flow [13] [29] [30] [31]. Per Fritz et al. [13], for our bucket grab samples, a bucket with the bottom removed and serrated edges, was screwed into the sediment. The top $\sim 10 \mathrm{~cm}$ of sediment was stirred by hand, and then immediately a hand net was passed through the water column for ten seconds to collect macroinvertebrates and sediment. This stirring and netting process within the sample area was repeated three times. Contents of the net were 
placed into a $250 \mu \mathrm{m}$ sieve. The sediments in these pools where grab samples were taken consisted mostly of sand, silt, and fine gravel. The net contents from grab samples were also augmented with the scrapings from $3-4$ rocks in the pool. Samples were placed in jars and preserved in $80 \%$ ethanol.

\subsection{Macroinvertebrate Identification}

Prior to sorting, samples were split in half. If a sort of half the sample resulted in a count of less than 100 , then the other half was sorted as well, for a total count. Though it would have been preferable to do a subsample count of 300 - 500 individuals as many state agencies do [8], this was not possible due to low abundance in most of the samples from deployed samplers. However, the lower subsample count of 100 is not uncommon among state agencies [7]. For samples where counts are derived from a sort of half of the sample, the other half received a qualitative sorting for any taxa not found in the initial half. If found, these additional taxa were included in taxa richness measures. Macroinvertebrates were identified to genus or species using keys by Merritt et al. [32], Epler [33], and Simpson and Bode [34]. Chironomid specimens were subsampled for genus- or species-level identification proportionally to the relative abundance across chironomid tribes.

\subsection{Statistical Analysis}

One-way Analysis of Variance (ANOVA) tests were run in SigmaPlot ${ }^{\mathrm{TM}} 14$ to compare taxa richness and abundance between methods. Data that passed the Shapiro-Wilk normality test were analyzed using the Holm-Sidak multiple comparison procedure. Data that did not pass the normality test were analyzed by the nonparametric Kruskal-Wallis test. The Invertebrate Community Index (ICI), which is the Ohio EPA's principle measure of overall macroinvertebrate community condition [17] and consists of 10 structural community metrics, was calculated for each sample.

Nonmetric Multidimensional Scaling (NMDS) ordinations and Multi-Response Permutation Procedure (MRPP) analyses [35] were conducted and graphs were generated using PC-ORD ${ }^{\mathrm{mm}}$ software [36]. A Sorenson (Bray-Curtis) distance measure was used in the NMDS analyses. MRPP was used to test whether there were significant differences among methods or between locations. MRPP analyses were run using a Relative Sorenson distance measure and the distance measure was rank transformed. The test statistic, $\mathrm{T}$, describes the separation between groups by comparing an observed delta to an expected delta. The more negative $\mathrm{T}$ is, the stronger the separation [35] of groups. The observed delta represents the average within-group distance. The calculated expected delta represents the mean delta for all possible partitions of the data. The agreement statistic, A, is the chance-corrected within-group agreement or homogeneity. An A of 1.0 would indicate that all taxa are identical within groups. In practice, values for $\mathrm{A}$ are commonly below $0.1 ; \mathrm{A}>0.3$ is considered fairly high [35]. The p value is 
used to evaluate how likely an observed difference is due to chance, i.e., the likelihood of getting a delta (the average within-group distance) as small, or smaller than the observed delta.

\section{Results}

Water depths above the deployed samplers ranged from 18 to $50 \mathrm{~cm}$ (avg. $=35$ $\mathrm{cm}, \mathrm{SD}=10)$ upon deployment and from 3 to $35 \mathrm{~cm}$ (avg. $=20 \mathrm{~cm}, \mathrm{SD}=11.5)$ upon retrieval, with the pool just upstream of the culvert being slightly shallower than the more permanent pool downstream of the culvert. There was a slight flow upon deployment; averaging $0.047 \mathrm{~m} / \mathrm{s}$ above the culvert and $0.020 \mathrm{~m} / \mathrm{s}$ downstream of the culvert, and no measurable flow at either site upon retrieval.

All 5 trays and 4 of 5 MHDs were retrieved from the pool above the culvert, though many of these were buried by sediment. From the pool below the culvert, only 2 of the 5 pairs of deployed samplers (2 MHDs and 2 trays) were retrieved and these were also buried by sediment (though not as deeply buried as the upstream samplers). It is believed that the samplers that could not be found below the culvert were washed away, possibly due to the pipe that makes up the culvert concentrating and speeding up the flow when it is filled to capacity in large rain events. Congress Run experienced a quite large surge due to a rain event just a few days after MHDs and trays were deployed (April 26, 2017). Starting in the early morning of April 28, in a matter of about 12 hours the stream rose over 2.2 $\mathrm{m}$ from a base flow of just a trickle (Figure 5), to overflowing its banks. The base flow of approximately $1 \mathrm{~m}$ in this graph does not represent $1 \mathrm{~m}$ depth of water, but a minimal base flow. The graph of stream stage (height) during the deployment period in Figure 5 demonstrates the flashy nature of this urban stream, showing this and other smaller but significant rain events. Stage of water is used in the graph, as discharge was not yet available from the U.S. Geological Survey (USGS) for this gage. The extent to which samplers were buried and the significant amounts of sediment that accumulated, especially in the gravel trays, are

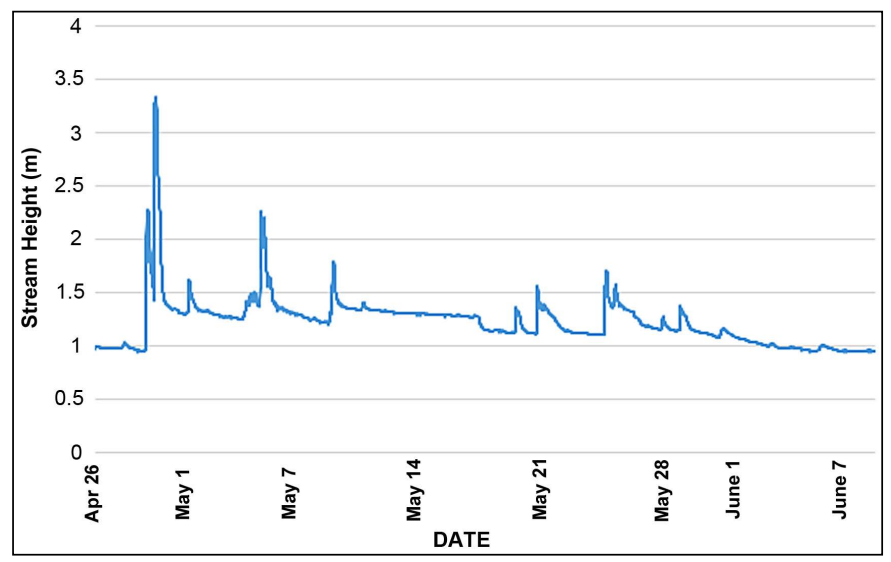

Figure 5. Stream stage measurements for the period of deployment of Hester-Dendy and gravel tray samplers, showing the surges in stream height caused by rain events. Measurements are from USGS stream gage 03259198 (Congress Run near Carthage OH). 
also testament to the large amounts of sediment deposited with the flashy flows that accompanied each significant rain event. Though the heavy rain event and associated surge in stream height and discharge that occurred within a few days of deployment of MHDs and trays (first 2 peaks in Figure 5) were quite large, this kind of surge is not unusual in this watershed.

There was a marginally insignificant difference $(\mathrm{p}=0.052)$ in percent organic content of the sediments among the methods. The tray method recovered a significantly greater dry mass of sediment (median $=496 \mathrm{gm}, \mathrm{p}<0.001$ ) than either the $\mathrm{MHD}($ median $=172 \mathrm{gm}$ ) or bucket method (median = $59 \mathrm{gm})$. By sieving sediment after sorting out the macroinvertebrates, we were able to do a general examination of some particle size classes [23]; sand $(250 \mu \mathrm{m}-2 \mathrm{~mm})$, fine to medium gravel $(2 \mathrm{~mm}-5.6 \mathrm{~mm})$, and medium to coarse gravel $(>5.6 \mathrm{~mm})$. The bucket and tray methods agreed well with respect to the fraction of sand and larger particles that they collected, with the makeup of sediment deposited for each one being about $35 \%$ sand $(250 \mu \mathrm{m}$ to $2 \mathrm{~mm})$ and around $60 \%$ gravel ( $>2$ $\mathrm{mm})$. These two methods also agreed in that $77 \%$ of the gravel fraction was medium to coarse gravel $(>5.6 \mathrm{~mm})$, with a visual inspection showing the majority of these rocks being $>10 \mathrm{~mm}$, many greater than $20 \mathrm{~mm}$. By comparison, the MHDs collected $49 \%$ sand ( $250 \mu \mathrm{m}$ to $2 \mathrm{~mm}$ ), $48 \%$ gravel ( $>2 \mathrm{~mm}$ ), with less of the gravel fraction $(\sim 30 \%)$ being medium to coarse gravel $(>5.6 \mathrm{~mm})$. The tray samples had the greatest dry weight of sediment collected in them (avg. $=278$ gm), followed by the MHD samples (avg. = $164 \mathrm{gm}$ ) and bucket grab samples (avg. = 107 gm).

\subsection{Usability}

We were able to easily sample 1 - 2 sites per day (with 5 replicate samplers per site) with one person using the bucket method. With sample handling, transport to the lab and sample processing at the lab (sieving, sampler disassembly and scraping (MHDs)), it took two people a full day to complete one site (with both trays and MHDs). There were also differences seen in sample sorting time, with tray samples taking over 7 hours per sample to sort, and bucket and MHD samples taking approximately 4.5 hours per sample. For all but one of the deployed samplers, the whole sample was sorted for a total count of organisms present. For the bucket grab samples, which had far greater total numbers, total counts were done for only two of the ten samples. For the other 8 samples, one-half of the sample was sorted and identified.

\subsection{Variability}

The bucket grab method had the lowest coefficient of variation (CV) for a number of common taxa richness and abundance metrics, as well as for the ICI multi-metric index of water quality (Table 1). The bucket grab method also had the lowest CV for number of dipteran taxa, and Chironomini, Tanytarsini, and Tanypodinae abundance. For Oligochaete (Table 1) and Orthocladiinae abundance, 
Table 1. Coefficients of Variation (CV) (percent) for the 3 sampling methods and all deployed samplers (MHD + tray) for some common metrics.

\begin{tabular}{|c|c|c|c|c|c|c|c|c|}
\hline & & $\begin{array}{l}\# \\
\text { Taxa }\end{array}$ & $\begin{array}{c}\# \\
\text { Chironomid Taxa }\end{array}$ & $\begin{array}{c}\# \\
\text { Non-chironomid Taxa }\end{array}$ & Abundance & $\begin{array}{l}\text { Abundance } \\
\text { Chironomids }\end{array}$ & $\begin{array}{l}\text { Abundance } \\
\text { Oligochaetes }\end{array}$ & $\begin{array}{c}\text { ICI } \\
\text { Rating }\end{array}$ \\
\hline \multirow{4}{*}{ Method } & Bucket & 20.9 & 23.5 & 35.6 & 54.6 & 65.3 & 100.4 & 27.4 \\
\hline & MHD & 42.9 & 41.4 & 62.0 & 80.5 & 117.7 & 81.8 & 56.4 \\
\hline & Tray & 53.9 & 55.5 & 57.7 & 77.6 & 140.4 & 85.4 & 70.5 \\
\hline & Deployed & 48.4 & 48.5 & 59.9 & 79.0 & 129.1 & 83.6 & 62.4 \\
\hline
\end{tabular}

the CVs for the bucket grab method were the highest of the three methods.

\subsection{Macroinvertebrate Community Retrieval Completeness}

Table 2 shows the taxa that were collected in this reach of Congress Run. The majority (30 of 43) of taxa collected were of the order Diptera. For this spring sampling, no individuals from the Ephemeroptera, Plecoptera, and Trichoptera (EPT) taxa were found in any of the samples.

ANOVAs showed some differences in taxa richness among methods. The bucket grab sample method produced a greater taxa richness per sample (Figure $6(\mathrm{a}))$ than the MHD ( $\mathrm{p}=0.003)$ and tray $(\mathrm{p}<0.001)$ methods. No difference was seen in taxa richness between the MHD and tray $(p=0.147)$ methods. The bucket grab method collected a significantly higher number of chironomid taxa per sample (Figure 6(b)) than the tray $(\mathrm{p}<0.001)$ and MHD $(\mathrm{p}=0.047)$ methods. There was a significant difference in number of chironomid taxa between the MHD and tray methods $(\mathrm{p}=0.047)$. The bucket grab method collected more non-chironomid taxa per sample (Figure 6(c)) than the MHD (Kruskal-Wallis; $p=0.003)$ and tray $(p=0.007)$ methods. No difference was seen in number of non-chironomid taxa between the MHD and tray $(p=1.000)$ methods.

In addition to analysis of the mean of taxa richness per sample, we calculated the total taxa collected from all the replicate samples of the methods (Figure 7). The number of taxa retrieved from all the bucket grab samples (42) was very close to the number of taxa retrieved from all samples, all methods (43). The MHDs retrieved 24 taxa and the trays retrieved 17 total taxa. There were more bucket grab samples collected (10) than MHD (6) or tray (7). However, the combined total taxa collected from of all 13 deployed samplers (MHD + tray), was also lower (27) than the total collected from 10 bucket grab samples (42).

The Bucket method provided a significantly higher abundance per sample (Figure 8) than the MHD ( $\mathrm{p}=0.007)$ and tray $(\mathrm{p}=0.005)$ methods. No difference was seen in abundance between MHD and tray $(p=1.000)$ samplers.

The dominant taxonomic groups in all samples were Chironomidae and Oligochaeta; however, the sample makeup of these groups varied with method (Figure 9). With few exceptions, Chironomidae were the dominant taxonomic group retrieved with the bucket grab sampler while Oligochaeta were dominant for the trays and MHD samplers. The communities from the bucket grab 


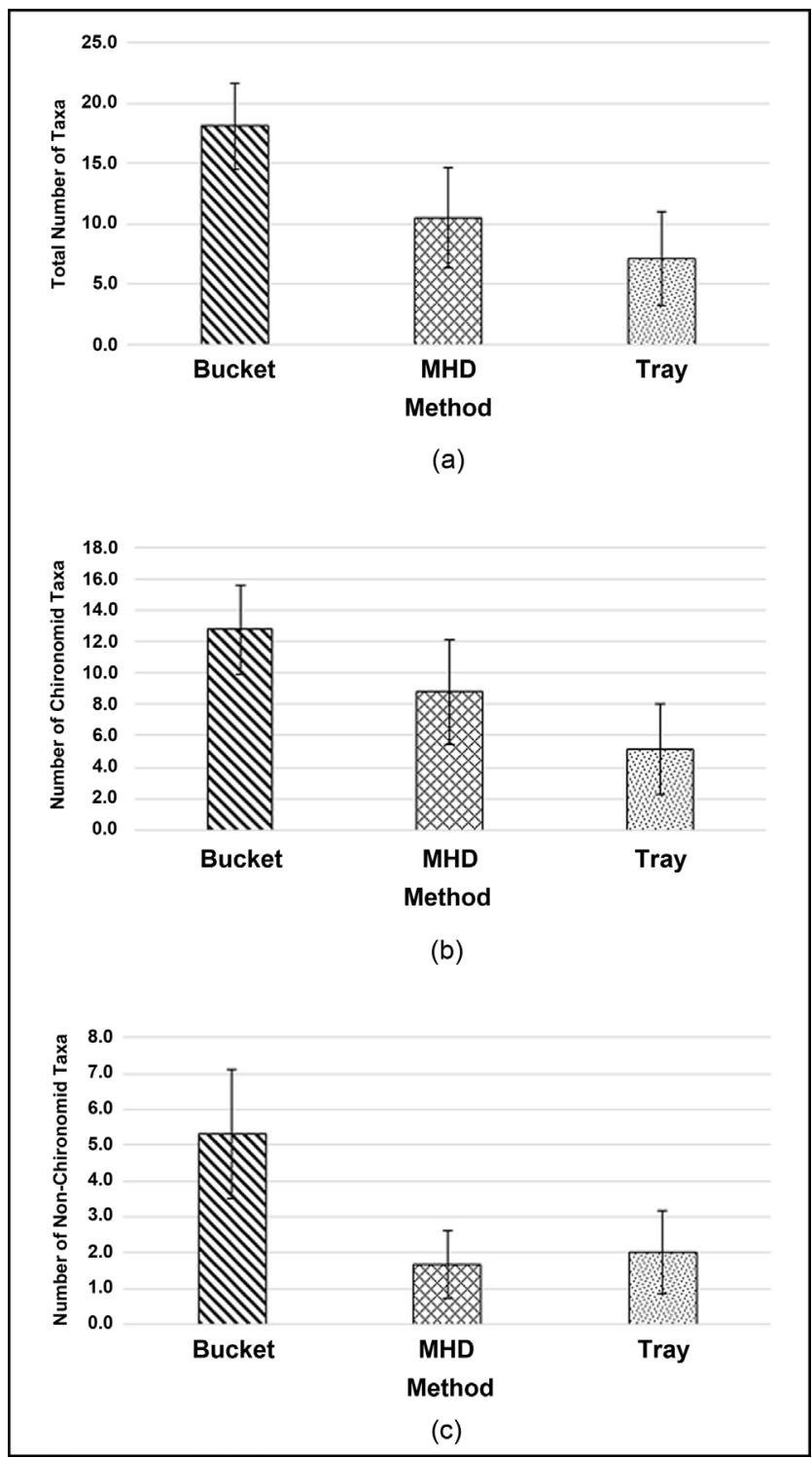

Figure 6. Macroinvertebrate taxa richness metrics by sampling method (a) mean total taxa richness $\pm 1 \mathrm{SD}$; (b) mean chironomid taxa richness $\pm 1 \mathrm{SD}$; (c) mean non-chironomid taxa richness $\pm 1 \mathrm{SD}$.

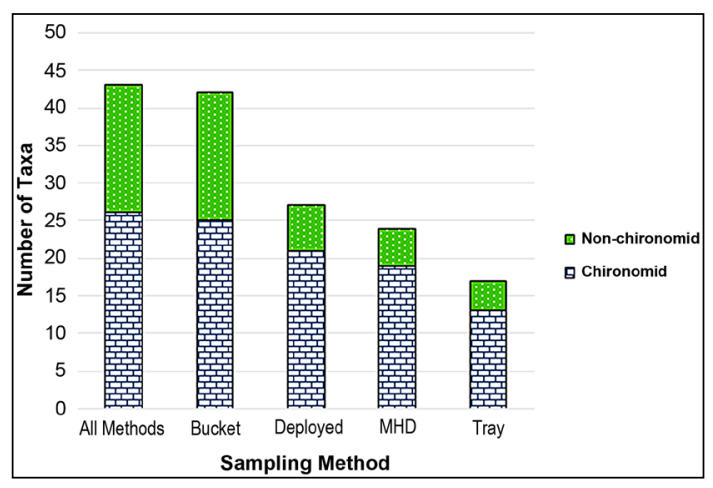

Figure 7. Total number of taxa collected from all the replicates of each method and combinations of methods (all deployed samplers (MHD + Tray) and all methods). 


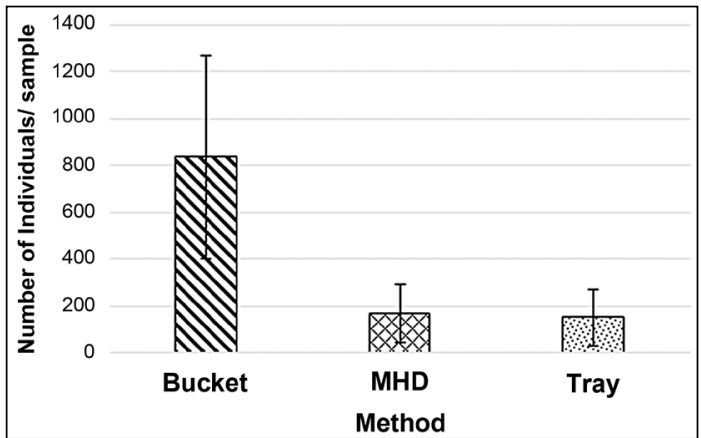

Figure 8. Comparison of mean abundances \pm 1 SD collected by the 3 methods.

Table 2. List of taxa retrieved by all methods (bucket + MHD + tray) in the 2017 spring sampling of the section of Congress Run upstream and downstream of the culvert, just above the confluence of Congress Run with Mill Creek.

\begin{tabular}{|c|c|}
\hline Chironomid Taxa & Non-Chironomid Taxa \\
\hline Ablabesmyia sp. & Oligochaeta \\
\hline Alotanypus sp. & Collembola \\
\hline Zavrelimyia sp. & Undetermined Diptera \\
\hline Psectrotanypus & Ephydridae \\
\hline Procladius & Atrichopogon sp. \\
\hline Conchapelopia sp. & Culicidae \\
\hline Corynoneura sp. & Undetermined Hirudinea \\
\hline Cricotopus bicinctus & Nematoda \\
\hline Cricotopus/ Orthocladius gr. & Isopoda/ Caecidotea sp. \\
\hline Thienemanniella xena & Gastropoda \\
\hline Eukiefferiella claripennis & Ancylidae \\
\hline Chironomus sp. & Lymnaeidae \\
\hline Cryptochironomus & Physidae \\
\hline Dicrotendipes sp. & Pelecypoda \\
\hline Dicrotendipes simpsoni & Elmidae \\
\hline Microtendipes sp. & Turbellaria \\
\hline Paratendipes sp. & Hydra sp./Hydroida \\
\hline \multicolumn{2}{|l|}{ Phaenopsectra punctipes } \\
\hline \multicolumn{2}{|l|}{ Phaenopsectra obediens } \\
\hline \multicolumn{2}{|l|}{ Polypedilum illinoense gr. } \\
\hline \multicolumn{2}{|l|}{ Polypedilum fallax } \\
\hline \multicolumn{2}{|l|}{ Polypedilum scalaenum gr. } \\
\hline \multicolumn{2}{|l|}{ Micropsectra sp. } \\
\hline \multicolumn{2}{|l|}{ Paratanytarsus sp. } \\
\hline Rheotanytarsus sp. & \\
\hline Tanytarsus sp. (Prob. guerlus) & \\
\hline
\end{tabular}




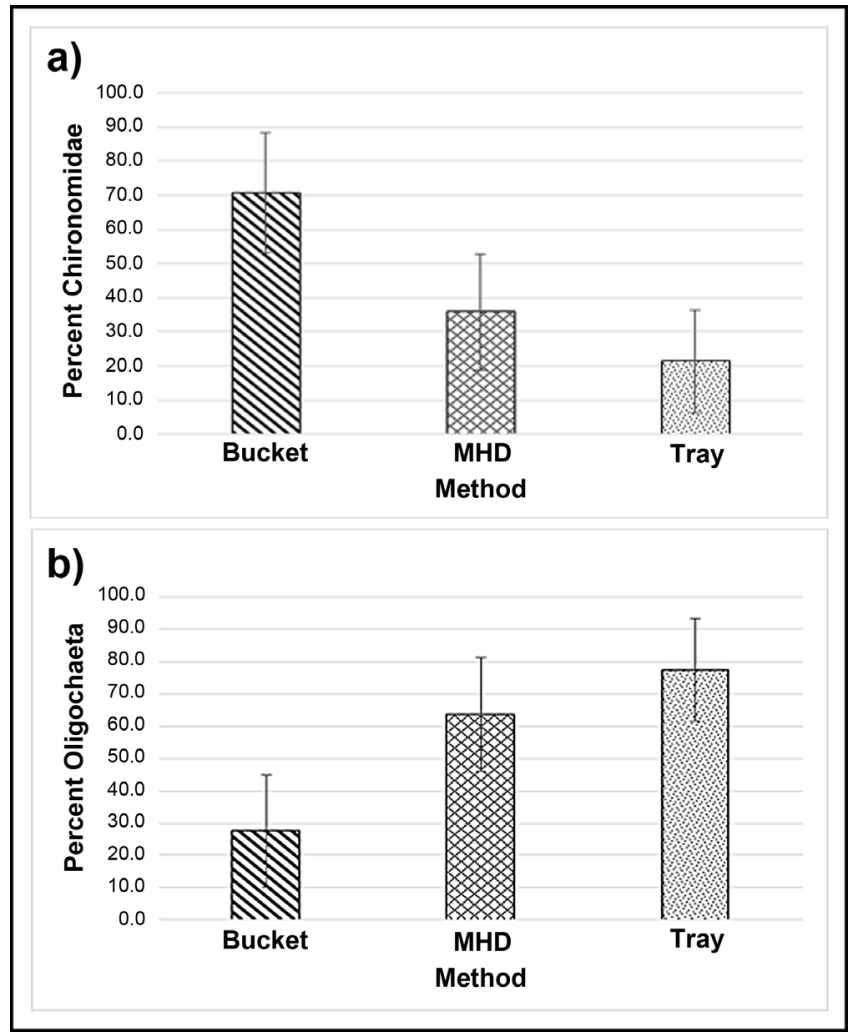

Figure 9. Average percentage \pm 1 SD of (a) chironomid abundance and (b) oligochaete abundance per sample.

samples had a significantly higher mean percentage $(71 \%)$ of chironomids (Figure 9(a)) than those from the MHDs $(36 \%, \mathrm{p}=0.002)$ or trays $(28 \%, \mathrm{p}<$ 0.001). The communities from the bucket grab samples had a significantly lower mean percentage $(28 \%)$ of oligochaetes (Figure 9(b)) than those from the MHDs $(63 \%, \mathrm{p}=0.002)$ or trays $(77 \%, \mathrm{p}<0.001)$.

Figure 10 shows the mean Invertebrate Community Index (ICI) scores [17] calculated from the macroinvertebrates retrieved by each method. There were no statistically significant differences in ICI scores, between methods. Based on these ICI scores, 15 of the 23 samples (all methods) resulted in a water quality rating of "Poor", and 8 samples had a rating of "Very Poor", with an overall average rating for this section of Congress Run (pooling upstream and downstream pool samples) of "Poor". The upstream pool had an overall rating (all methods) of "Very Poor", and the downstream pool had an overall rating (all methods) of "Poor". The rating of this section of the stream (pooling upstream and downstream pool samples), varied by method. Averaging all the bucket replicate samples into one rating resulted in a water quality rating of "Poor". Doing the same for the MHD or tray replicates resulted in a "Very Poor" rating. Each method had samples with a "Very Poor" rating. All of the samples with "Very Poor" ratings were from the pool above the culvert. Other than total taxa, which is one metric of the ICI, other ICI metrics that responded differently among methods were the total number of dipteran taxa and percent tolerant organisms. 


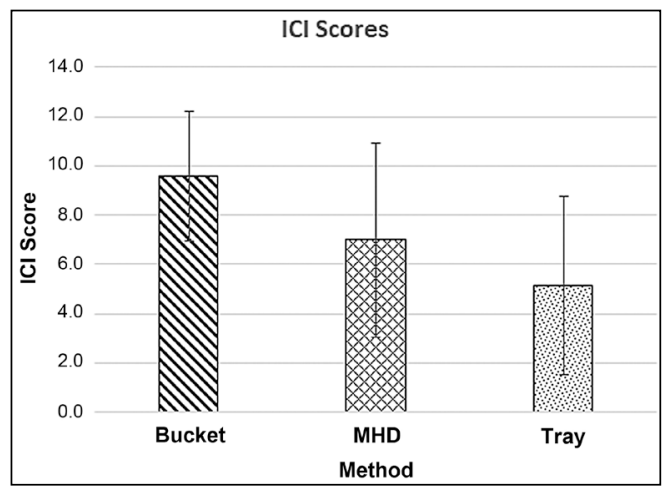

Figure 10. Comparison of mean ICI scores \pm 1 SD calculated by the 3 methods.

For the total number of dipteran taxa metric, an ANOVA indicated that the bucket method had a greater mean number of taxa (13.9) than the tray method $($ mean $=5.7, \mathrm{p}<0.001)$ and the MHD method (mean $=8.2, \mathrm{p}=0.009)$. For the percent tolerant organisms metric, the bucket method had a lower percentage of tolerant taxa $(56.0 \%)$ than the tray method (mean $=82.1 \%, \mathrm{p}=0.028)$, but not the MHD method $($ mean $=75.6 \%, p=0.067)$. The percent tribe tanytarsini, and other diptera and non-insects metrics showed no difference between methods. For the five metrics that involved the EPT taxa there were of course no differences seen between methods as there were no EPT taxa retrieved from the pools in this particular sampling.

Multivariate analyses (NMDS and MRPP) revealed some significant differences in the macroinvertebrate assemblages when grouped by method (Figure 11), or by location (Figure 12). The NMDS analysis showed a good fit, with a stress of 4.93 .

The graphic representation of the NMDS in Figure 12, shows the grouping of macroinvertebrate assemblages retrieved by the bucket grab samples, and differences between these assemblages and those retrieved from the deployed samplers. There was also some grouping seen based on location, whether the samples were from the above or below the culvert (Figure 12).

MRPP analyses give statistical confirmation of the groupings seen visually in Figure 11 and Figure 12. An MRPP analysis run on the groups of samples representing the three methods (Figure 11) gives the following values: $\mathrm{T}=-6.15, \mathrm{p}$ $=0.0002$, and $\mathrm{A}=0.276$. When methods are grouped by bucket or deployed sampler (HD + tray), a larger difference between methods was seen, with a more negative T (-8.72), smaller p (0.00007), and a similar A (0.269) value. An MRPP analysis run on the groups of samples located above and below the culvert (NMDS shown in Figure 12) indicates significant differences in the communities: $\mathrm{T}=-6.48, \mathrm{p}=0.00061$, and $\mathrm{A}=0.200$.

\section{Discussion}

This study shows once again the importance of researching the best sampling method to meet specific waterbody conditions and study objectives. Hester-Dendy 


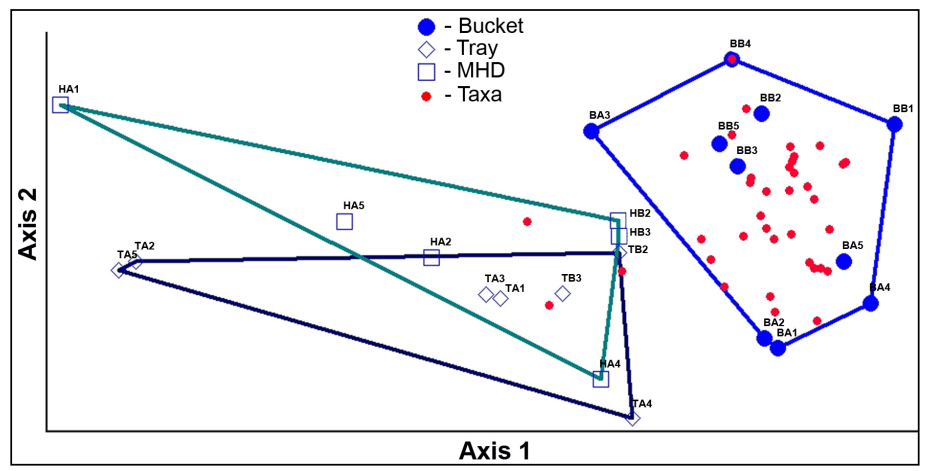

Figure 11. Grouping of macroinvertebrate assemblages by method. Results of nonmetric multidimensional scaling (NMDS) analysis of the samples plotted in taxa space showing grouping and similarity of the assemblages of the bucket method samples. [Sample codes: First letter indicates the method (B-bucket, $\mathrm{T}=$ tray, $\mathrm{H}=\mathrm{MHD}$ ); second letter indicates location ( $\mathrm{A}=$ above culvert, $\mathrm{B}=$ below culvert); number indicates the replicate.]

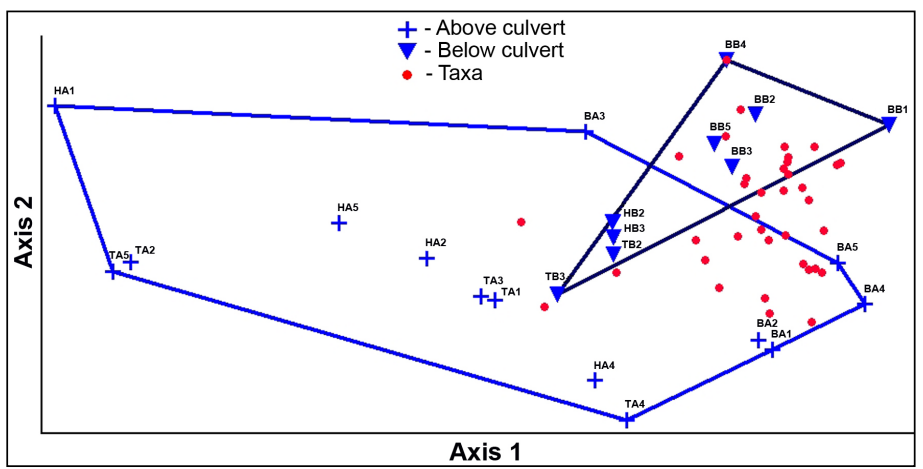

Figure 12. Grouping of macroinvertebrate assemblages by location. Results of nonmetric multidimensional scaling (NMDS) analysis of the samples plotted in taxa space showing grouping. [Sample codes: First letter indicates the method (B-bucket, $\mathrm{T}=$ tray, $\mathrm{H}=\mathrm{MHD}$ ); second letter indicates location ( $\mathrm{A}=$ above culvert, $\mathrm{B}=$ below culvert); number indicates the replicate.]

and rock basket/tray methods are widely used and useful in many situations. The effectiveness of gravel-filled colonization trays for characterizing the macroinvertebrate community has been demonstrated in previous studies [37] [38] [39]. Hester-Dendy samplers have been used with success by federal [14] and state [7] [15] [16] [18] [40] agencies. However, neither of these samplers, even when modified for this situation (low-profile MHD) represented the best method for this flashy urban stream. For streams with diverse communities, identification of macroinvertebrates to family level can be sufficient to detect spatial or temporal differences in water quality [41] [42]. However, for highly impacted streams like Congress Run, composed mostly of Chironomidae and Oligochaeta, identification of Chironomidae to lowest achievable level (usually genus or species), along with a focus on chironomid community-based metrics [43] [44], and multivariate statistical analyses like NMDS is likely necessary to detect these differences. Future analyses of water quality would warrant incorporation of analyses of chironomid traits and life history strategies [45] as an- 
other means of detecting changes in the level of anthropogenic disturbance.

The ICI is a well-established index, relevant to Ohio Streams, and includes Chironomidae metrics, thus useful for bioassessment of Congress Run. However, the ICI values and ratings calculated in this study should not be considered completely comparable to Ohio EPA ICI ratings, as our methods did not adhere to the Ohio EPA sampling protocols [15] [16] [17]. Deviances from the Ohio EPA method include that our MHDs were modified from the Ohio EPA design, we did not adhere to the recommended retrieval period of June 15 to September 30 , and the flow at our sites did not meet the $\geq 10 \mathrm{~cm} / \mathrm{sec}$ level that the Ohio EPA recommends for accurate interpretation of the ICI.

Though no EPT taxa were found in these spring sampling data, Ephemeroptera (Heptageniidae, Caenidae) were found in small numbers in other grab-samples. This available pool of taxa, along with additional taxa found in nearby Mill Creek (including a number of Trichoptera and Ephemeroptera taxa), indicates a potential for recovery of the ICI and water quality if enough green infrastructure and remediation efforts were undertaken within the watershed to significantly alter the flashy hydrology. Future research needs include collecting in the fall season, as well as exploring ways to further standardize the bucket method to reduce variability.

\subsection{Usability}

The bucket grab sampler required the least effort to sample, process, sort, and ID. The shorter time needed for sorting of the bucket samples makes sense in light of the lesser amount of sediment collected in the bucket samples compared to samples from the deployed samplers, and the lower abundance of the deployed samplers (especially the tray samplers). Therefore, a larger volume of sediment had to be picked through (usually representing the entire sampler) for the deployed samplers in an attempt to get to a minimum subsample of 100 organisms. The bucket sampler was the only one which resulted in a complete set of 5 samples from each sampling site.

The MHDs and trays were candidates for use in urban streams, in large part because they don't require flow to collect a sample, like many commonly used samplers (Hess, Surber, kick net) and thus could be used in the isolated pools found for a large part of the year in flashy urban streams. However, this advantage was largely counteracted by being buried and swept away by periodic spates. Since the USGS gage on Congress Run is new, there is insufficient historical data to compare stream surges on Congress Run during our deployment period to stream surges that might bury or sweep away deployed samplers over multiple years. However, there is a nearby gage on Mill Creek (USGS 03259000 Mill Creek at Carthage $\mathrm{OH}$ ) in the same watershed that can be used to compare multiple years of stream hydrology. In 5 of the 7 years from 2012-2018, 2 to $3 \mathrm{~m}$ surges occurred during our spring deployment period (April 26 through June 8) at this nearby gage on Mill Creek. In 2012 and 2017 there was a surge of the same height $\left(\sim 3^{1 / 2} \mathrm{~m}\right)$ at this Mill Creek gage, that corresponded to the surge 
seen on Congress Run April 28-29 in 2017 (Figure 5).

An attempt was made to include another stream in this methods study; one expected to be less affected by urban disturbances, the West Fork of the Mill Creek. The West Fork runs through a forested city park and is of similar size to Congress Run, but its watershed has less industrialization and urbanization. This stream turned out to have even more powerful surges from rain events (perhaps due to a steeper slope), and all of the MHD and tray samplers were washed away. In addition, we had issues with vandalism. For these reasons, the bucket grab sampler was the only one of our 3 methods suitable for this location.

Other researchers have also experienced some of the usability issues of artificial samplers associated with high flow that we found in this study. Roby et al. [46] found that artificial samplers "were lost, became clogged or buried". Kirk and Perry [47] reported that multi-plate samplers were washed downriver at high flows. Monitoring programs have tried to account for flow issues by incorporating different means of anchoring the samplers. Though attaching the deployed samplers to rebar driven into the sediment (in addition to the attached weights) may help somewhat in keeping the samplers in place during spates, we had mixed success with attempts to do this, and this added measure did nothing to keep the samplers from being buried or to ensure that the samplers will remain within the flowing portion of the channel. The state of Iowa [18] uses a type of Hester-Dendy sampler which a modified for low flow conditions, with rods holding the samplers above the surface of the sediment. This design can apparently help with the issue of burial, but the IDNR methods also acknowledge the possibility of damage from high flows.

\subsection{Variability}

The variability for all of these methods was higher than desired for a number of metrics. However, for total taxa richness, the most commonly used metric by U.S. state agencies [8], the bucket method performed well with respect to variability (CV of 20.9\%). It also had the lowest CV for the ICI multi-metric index (Table 1), giving this method greater ability to detect differences in water quality between site samplings. The abundance values from the bucket grab samplers varied greatly (Figure 8) but, due to higher abundances, did not have a higher $\mathrm{CV}$. Though the variability associated with the tray and MHD samplers was higher than that of the bucket grab samplers for this study, one would not expect that result to necessarily extend to their use in non-flashy streams. The results from previous studies of comparisons of the variability of grab samplers versus deployed artificial substrate samplers are mixed. Some studies have found that artificial substrate samplers had lower variability [38] [39] [46] [48] while others have found grab samplers to have a lower variability [49] [50]. Based on long-term use, Hester-Dendy multi-plate samplers have shown a variability which is acceptable for use for monitoring and assessing water quality in lotic and lentic waterbodies by state programs including Ohio [15] [16] and New York [40], and by the U.S. EPA [14]. However, these programs utilize modified 
Hester-Dendy samplers and to a lesser extent rock-filled trays, primarily to monitor waterbodies with a greater hydrological permanence (rivers, perennial streams, lakes) than exhibited by flashy urban streams. The MHD and tray samplers ranged from being partly to completely buried. Some of these replicates that were buried the deepest had very low abundances ( $<20$ individuals), which likely contributed to the higher variability of MHDs and trays.

\subsection{Macroinvertebrate Community Retrieval Completeness}

Multiple factors may potentially contribute to the differences in assemblages seen between methods, including the greater abundance and diversity seen in the communities retrieved by the bucket method. First, the significantly greater area/footprint of the bucket sampler should be considered a prime factor. The cross-sectional area of the MHD is approximately half that of the cross-sectional area of the trays and about $20 \%$ of the cross-sectional area of the bucket. Though the additional scraped rocks would add to the area of the bucket method, qualitative observations during sampling were of no noticeable macroinvertebrate presence on the rocks. Also, the macroinvertebrate taxa we had hoped to find from this extra sampling activity, which might utilize the surfaces of the rocks (Trichoptera, Ephemeroptera), were not found in any of the bucket samples. Researchers interested in using the bucket method, for whom it is more important to be able to calculate an accurate area for density calculations than maximizing the number of taxa retrieved, or where there is no noticeable macroinvertebrate presence on rocks in the sampling area, may not want to include these extra rocks as part of the sampling method.

Another potential factor affecting differences in communities is differences in particle size distribution between methods. Several studies [51] [52] [53] [54] [55] have found an effect of substrate particle size on the makeup of benthic macroinvertebrate assemblages, with different taxa having preferences for different particle sizes. One quantified particle size difference in this study was that of the MHDs having less of the medium to coarse gravel-sized particles ( $>5.6$ $\mathrm{mm}$ ) than the other methods. This makes sense due to the small openings (2 - 3 $\mathrm{mm}$ ) between plates in these samplers, which would represent an obstruction to larger sized particles. In addition, though the silt portion of sediments was not collected and quantified during sample processing, observations during sampling and sample processing were of the substrate in pools where the bucket samples were taken having a higher proportion of silt than was present in the MHD and tray samples.

The deployed samplers being buried in deposited sediment early in the sampling period represent another potential factor affecting differences in macroinvertebrate assemblages between methods. Artificial substrate samplers like the gravel tray and MHD, can provide macroinvertebrate habitat that is not abundant in pools like the ones in Congress Run, which have a substrate of mostly sand and small to medium gravel. This introduced habitat, including hard surfaces and spaces for attachment and refuge, brings with it the potential to re- 
trieve some additional taxa from these pools. However, this potential is lost when these samplers are buried in sediment when spates and the associated sediment deposition occur. Since the sediment on top of the gravel tray and MHD samplers is not collected and analyzed, the habitat assessed in these deployed samples is different from that assessed by the bucket sampler. In the bucket method, approximately the top $10 \mathrm{~cm}$ of sediment is stirred up and sampled, so macroinvertebrates are retrieved from a range of depths, from the sediment surface down to $10 \mathrm{~cm}$. Therefore, the tray and MHD samplers, whose surfaces were several $\mathrm{cm}$ below the surface by time of retrieval, would generally be collecting macroinvertebrates from a narrower, deeper sediment habitat than the bucket grab samples. The differences in habitat sampled by the different methods likely contribute to the differences in the assemblages retrieved by the 3 sampling methods. These differences in habitat sampled could help to explain why Chironomidae were the dominant taxonomic group retrieved by the bucket grab samples, while Oligochaeta were dominant in the assemblages from the deployed samplers (Figure 9). Taxa may have preferences regarding the depth in the sediment at which they reside. For example, Williams and Hynes [56] recovered Oligochaeta from significantly deeper levels of the sediments than Chironomidae. It is quite possible that higher percentages of Chironomidae in the assemblages retrieved from the bucket samplers contributed to the higher chironomid and total taxa richness for the bucket grab sampler versus the deployed methods.

Due to these multiple factors that could potentially affect the differences in assemblages among sampling methods, we did not attempt a quantitative normalization by area among methods nor focus on analysis of method differences based on a comparison of densities. This follows the example of researchers in previous studies that compared artificial substrate samplers (rock baskets, multi-plate, or webbing) and grab samplers (fixed area (e.g., Surber) and/or dredge (e.g., Ponar) and did not attempt such a normalization [46] [49] [55] [57] [58] [59]. Only a few U.S. State agencies use density as a metric, while measures of richness are by far the most popular type of metric used by these agencies [8]. Therefore, for most studies, which method will more completely retrieve the number of taxa living in the stream will likely be a key consideration in the decision in the choice of sampling method.

The bucket grab sampling method performed best with respect to our criteria of usability, variability, and community retrieval, and will be used going forward to assess the green infrastructure/restoration effort in Congress Run. The bucket grab sampler has the potential to help fill the methods gap that exists for quantitative sampling of macroinvertebrates in flashy urban streams, whose flow regimes pose problems for commonly used grab and deployed sampling methods.

\section{Acknowledgements}

We thank Haley Wright and Chelsea Hintz for their contributions in the laboratory and field. Thanks to our colleague Jim Lazorchak for his guidance and 
support.

\section{Disclaimer}

The views expressed in this article are those of the authors and do not necessarily represent the views or policies of the U.S. Environmental Protection Agency.

\section{Conflicts of Interest}

The authors declare no conflicts of interest regarding the publication of this paper.

\section{References}

[1] US Environmental Protection Agency (USEPA) (2000) The Quality of Our Nation's Waters. Office of Water (4503F), Washington DC.

[2] Booth, D.B. Karr, J.R., Schauman, S., Konrad, C.P., Morley, S.A., Larson, M.G. and Burges, S.J. (2004) Reviving Urban Streams: Land Use, Hydrology, Biology, and Human Behavior. Journal of the American Water Resource Association, 40, 1351-1364. https://doi.org/10.1111/j.1752-1688.2004.tb01591.x

[3] Konrad, C.P. and Booth, D.B. (2005) Hydrologic Changes in Urban Streams and Their Ecological Significance. American Fisheries Society Symposium, 47, 157-177.

[4] Hawley, R.J., Wooten, M.S., Macmannis, K.R. and Fet, E.V. (2016) When Do Macroinvertebrate Communities of Reference Streams Resemble Urban Streams? Freshwater Science, 35, 778-794. https://doi.org/10.1086/687808

[5] Baker, D.B., Richards, P., Loftus, T.T. and Kramer, J.W. (2004) A New Flashiness Index: Characteristics and Applications to Midwestern Rivers and Streams. Journal of the American Water Resource Association, 40, 503-522. https://doi.org/10.1111/j.1752-1688.2004.tb01046.x

[6] Walsh, C.J., Roy, A.H., Feminella, J.W., Cottingham, P.D., Groffman, P.M. and Morgan, R.P. (2005) The Urban Stream Syndrome: Current Knowledge and the Search for a Cure. Freshwater Science, 24, 706-723. https://doi.org/10.1899/04-028.1

[7] Carter, J.L. and Resh, V.H. (2001) After Site Selection and before Data Analysis: Sampling, Sorting, and Laboratory Procedures Used in Stream Benthic Macroinvertebrate Monitoring Programs by USA State Agencies. Journal of the North American Benthological Society, 20, 658-682.

https://doi.org/10.2307/1468095

[8] Carter, J.L. and Resh, V.H. (2013) Analytical Approaches Used in Stream Benthic Macroinvertebrate Biomonitoring Programs of State Agencies in the United States. US Geological Survey, Reston, VA. https://doi.org/10.3133/ofr20131129

[9] US Environmental Protection Agency (USEPA) (1996) Summary of State Biological Assessment Programs for Streams and Rivers. Office of Policy, Planning and Evaluation, Washington DC.

[10] Goodrich, C., Huggins, D.G., Everhart, R.C. and Smith, E.F. (2005) Summary of State and National Biological and Physical Habitat Assessment Methods with a Focus on EPA Region 7 States. Kansas Biological Survey, Central Plains Center for Bioassessment, Lawrence, KS.

[11] Ohio Environmental Protection Agency (2011) Ohio EPA Surface and Ground Waters Monitoring Strategy 2011-2015. Division of Surface Waters and Division of Drinking and Ground Water, Columbus, $\mathrm{OH}$. 
[12] Buss, D.F., Carlisle, D.M., Chon, T.S., Culp, J., Harding, J.S., Keizer-Vlek, H.E., Robinson, W.A., Strachan, S., Thirion, C. and Hughes, R.M. (2014) Stream Biomonitoring Using Macroinvertebrates Around the Globe: A Comparison of Large-Scale Programs. Environmental Monitoring and Assessment, 187, Article No. 4132. https://doi.org/10.1007/s10661-014-4132-8

[13] Fritz, K.M., Johnson, B.R. and Walters, D.M. (2006) Field Operations Manual for Assessing the Hydrologic Permanence and Ecological Condition of Headwater Streams. US Environmental Protection Agency, Office of Research and Development, Washington DC.

[14] US Environmental Protection Agency (USEPA) (1990) Macroinvertebrate Field and Laboratory Methods for Evaluating the Biological Integrity of Surface Waters. Office of Research and Development, Washington DC.

[15] Ohio Environmental Protection Agency (1987) Biological Criteria for the Protection of Aquatic Life: Volume II. Users Manual for Biological Field Assessment of Ohio Surface Waters. Division of Water Quality Planning and Assessment, Ecological Assessment Section, Columbus, OH.

[16] Ohio Environmental Protection Agency (1989) Biological Criteria for the Protection of Aquatic Life. Volume III: Standardized Biological Field Sampling and Laboratory Methods for Assessing Fish and Macroinvertebrate Communities. Division of Water Quality Monitoring and Assessment, Columbus, $\mathrm{OH}$.

[17] Ohio Environmental Protection Agency (2015) Biological Criteria for the Protection of Aquatic Life: Volume III. Standardized Biological Field Sampling and Laboratory Methods for Assessing Fish and Macroinvertebrate Communities. Division of Surface Water, Ecological Assessment Section, Columbus, OH.

[18] Iowa Department of Natural Resources (IDNR) (2015) Biological Sampling and Physical Habitat Assessment Standard Operating Procedure for Iowa Wadeable Streams and Rivers. Revised by: IDNR Water Quality Monitoring and Assessment Section and the Limnology Section of the State Hygienic Laboratory at the University of Iowa, Iowa, IA.

[19] Ohio Environmental Protection Agency (2016) Ohio 2016 Integrated Water Quality Monitoring and Assessment Report. Division of Surface Water, Columbus, OH.

[20] Clohessy, E., Weidl, C., Moyer, J., Lehmann, A., Koehler, B., Wamsley, B., Miller, M. and Merrill, K. (2017) Nine-Element Nonpoint Source Implementation Strategic Plan (NPS-IS Plan), Congress Run-Mill Creek HUC-12 (050902030104). Mill Creek Watershed Council of Communities, Cincinnati, $\mathrm{OH}$.

[21] ASTM (2014) Standard Test Methods for Moisture, Ash, and Organic Matter of Peat and Other Organic Soils. American Society for Testing and Materials International, Philadelphia, PA.

[22] ASTM (2015) Standard Test Method for Ash in Biomass. American Society for Testing and Materials International. Philadelphia, PA, USA.

[23] Wentworth, C.K. (1922) A Scale of Grade and Class Terms for Clastic Sediments. Journal of Geology, 30, 377-392. https://doi.org/10.1086/622910

[24] US Environmental Protection Agency (USEPA) (2013) National Rivers and Streams Assessment 2013-2014: Field Operations Manual Wadeable. Office of Water, Washington DC.

[25] Cummins, K.W. (1962) An Evaluation of Some Techniques for the Collection and Analysis of Benthic Samples with Special Emphasis on Lotic Waters. American Midland Naturalist, 67, 477-504. https://doi.org/10.2307/2422722

[26] Bain, M.B., Finn, J.T. and Booke, H.E. (1985) Quantifying Stream Substrate for 
Habitat Analysis Studies. North American Journal of Fish Management, 5, 499-500. https://doi.org/10.1577/1548-8659(1962)91[420:AMSFAM]2.0.CO;2

[27] Plafkin, J.L., Barbour, M.T., Porter, K.D., Gross, S.K. and Hughes, R.M. (1989) Rapid Bioassessment Protocols for Use in Streams and Rivers: Benthic Macroinvertebrates and Fish. US Environmental Protection Agency, Assessment and Watershed Protection Division, Washington DC.

[28] Hester, F.E. and Dendy, J.S. (1962) A Multiple-Plate Sampler for Aquatic Macroinvertebrates. Transactions of the American Fisheries Society, 91, 420-421. https://doi.org/10.1577/1548-8659(1962)91[420:AMSFAM]2.0.CO;2

[29] Turner, A.M. and Trexler, J.C. (1997) Sampling Aquatic Invertebrates from Marshes: Evaluating the Options. Journal of the North American Benthological Society, 16, 694-709. https://doi.org/10.2307/1468154

[30] Difranco, J. (2006) Protocols for Sampling Aquatic Macroinvertebrates in Freshwater Wetlands. State of Maine Department of Environmental Protection, Bureau of Land and Water Quality, Augusta, ME.

[31] Weber, C.I. (1973) Biological Field and Laboratory Methods for Measuring the Quality of Surface Waters and Effluents. US Environmental Protection Agency, Environmental Monitoring Series, Washington DC.

[32] Merritt, R.W., Cummins, K.W. and Berg, M.B. (2008) An Introduction to the Aquatic Insects of North America. 4th Edition, Kendall Hunt Publishing Co., Dubuque, IA.

[33] Epler, J.H. (2001) Identification Manual for the Larval Chironomidae (Diptera) of North and South Carolina. North Carolina Department of Environment and Natural Resources, Raleigh, NC.

[34] Simpson, K.W. and Bode, R.W. (1980) Common Larvae of Chironomidae (Diptera) from New York State Streams and Rivers. New York State Education Department, Albany, NY.

[35] Mccune, B. and Grace, J.B. (2002) Analysis of Ecological Communities. MjM Software Design, Gleneden Beach, OR.

[36] Mccune, B. and Mefford, M.J. (2011) PC-ORD. Multivariate Analysis of Ecological Data. Version 6.21. MjM Software Design, Gleneden Beach, OR.

[37] Shaw, D.W. and Minshall, G.W. (1980) Colonization of an Introduced Substrate by Stream Macroinvertebrates. Oikos, 34, 259-271. https://doi.org/10.2307/3544285

[38] Clements, W.H., Van Hassel, J.H., Cherry, D.S. and Cairns, J. (1989) Colonization, Variability, and the Use of Substratum-Filled Trays for Biomonitoring Benthic Communities. Hydrobiologia, 173, 45-53. https://doi.org/10.1007/BF00008597

[39] Clements, W.H. (1991) Characterization of Stream Benthic Communities Using Substrate-Filled Trays: Colonization, Variability, and Sampling Selectivity. Journal of Freshwater Ecology, 6, 209-221. https://doi.org/10.1080/02705060.1991.9665295

[40] New York State Department of Environmental Conservation (2014) Standard Operating Procedure. Biological Monitoring of Surface Waters in New York State. Water Division, Albany, NY, SOP 208-214.

[41] Bowman, M.F. and Bailey, R.C. (1997) Does Taxonomic Resolution Affect the Multivariate Description of the Structure of Freshwater Benthic Macroinvertebrate Communities? Canadian Journal of Fisheries and Aquatic Sciences, 54, 1802-1807. https://doi.org/10.1139/f97-085

[42] Bailey, R.C., Norris, R.H. and Reynoldson, T.B. (2001) Taxonomic Resolution of Benthic Macroinvertebrate Communities in Bioassessments. Journal of the North 
American Benthological Society, 20, 280-286. https://doi.org/10.2307/1468322

[43] Langton, P.H. and Casas, J. (1999) Changes in Chironomid Assemblage Composition in Two Mediterranean Mountain Streams over a Period of Extreme Hydrological Conditions. Hydrobiologia, 390, 37-49. https://doi.org/10.1023/A:1003589216389

[44] Kosnicki, E. and Sites, R.W. (2007) Least-Desired Index for Assessing the Effectiveness of Grass Riparian Filter Strips in Improving Water Quality in an Agricultural Region. Environmental Entomolology, 36, 713-724. https://doi.org/10.1093/ee/36.4.713

[45] Serra, S.R.Q., Graca, M.A.S., Doledec, S. and Feio, M.J. (2017) Chironomidae Traits and Life History Strategies as Indicators of Anthropogenic Disturbance. Environmental Monitoring and Assessment, 189, Article No. 326. https://doi.org/10.1007/s10661-017-6027-y

[46] Roby, K.B., Newbold, J.D. and Erman, D.C. (1978) Effectiveness of an Artificial Substrate for Sampling Macroinvertebrates in Small Streams. Freshwater Biology, 8, 1-8. https://doi.org/10.1111/j.1365-2427.1978.tb01420.x

[47] Kirk, E.J. and Perry, S.A. (1994) A Comparison of Three Artificial Substrate Samplers: Macroinvertebrate Densities, Taxa Richness, and Ease of Use. Water Environment Research, 66, 193-198. https://doi.org/10.2175/WER.66.3.3

[48] Hughes, B.D. (1975) A Comparison of Four Samplers for Benthic Macro-Invertebrates Inhabiting Coarse River Deposits. Water Research, 9, 61-69.

https://doi.org/10.1016/0043-1354(75)90153-0

[49] Crossman, J.S. and Cairns, J. (1974) A Comparative Study between Two Different Artificial Substrate Samplers and Regular Sampling Techniques. Hydrobiologia, 44, 517-522. https://doi.org/10.1007/BF00036315

[50] Boothroyd, I.K.G. and Dickie, B.N. (1989) Macroinvertebrate Colonisation of Perspex Artificial Substrates for Use in Biomonitoring Studies. New Zealand Journal of Marine and Freshwater Research, 23, 467-478. https://doi.org/10.1080/00288330.1989.9516383

[51] Wene, G. and Wickliff, E.L. (1940) Modification of a Stream Bottom and Its Effect on the Insect Fauna. Thecanadian Entomologist, 72, 131-135. https://doi.org/10.4039/Ent72131-7

[52] Cummins, K.W. and Lauff, G.H. (1969) The Influence of Substrate Particle Size on the Microdistribution of Stream Macrobenthos. Hydrobiologia, 34, 145-181. https://doi.org/10.1007/BF00141925

[53] Allan, J.D. (1975) The Distributional Ecology and Diversity of Benthic Insects in Cement Creek, Colorado. Ecology, 56, 1040-1053. https://doi.org/10.2307/1936145

[54] Minshall, G.W. and Minshall, J.N. (1977) Microdistribution of Benthic Invertebrates in a Rocky Mountain (USA) Stream. Hydrobiologia, 55, 231-249. https://doi.org/10.1007/BF00017555

[55] Khalaf, G. and Tachet, H. (1980) Colonization of Artificial Substrata by Macro-Invertebrates in a Stream and Variations According to Stone Size. Freshwater Biology, 10, 475-482. https://doi.org/10.1111/j.1365-2427.1980.tb01220.x

[56] Williams, D.D. and Hynes, H.B.N. (1974) The Occurrence of Benthos Deep in the Substratum of a Stream. Freshwater Biology, 4, 233-256.

https://doi.org/10.1111/j.1365-2427.1974.tb00094.x

[57] Simmons Jr., G.M. and Winfield, A. (1971) A Feasibility Study Using Conservation Webbing as an Artificial Substrate in Microbenthic Studies. The Virginia Journal of 
Science, 22, 52-59.

[58] Slack, K.V., Ferreira, R.F. and Averett, R.C. (1986) Comparison of Four Artificial Substrates and the Ponar Grab for Benthic Invertebrate Collection. Water Resource Bulletin, 22, 237-248. https://doi.org/10.1111/j.1752-1688.1986.tb01880.x

[59] Humphries, P., Growns, J.E., Serafini, L.G., Hawking, J.H., Chick, A.J. and Lake, P.S. (1998) Macroinvertebrate Sampling Methods for Lowland Australian Rivers. Hydrobiologia, 364, 209-218. https://doi.org/10.1023/A:1003221602632 